\title{
L'Europe du Sud-Est et la presse allophone
}

\section{Nicolas Pitsos}

\section{(2) OpenEdition}

Journals

Édition électronique

URL : https://journals.openedition.org/ceb/16002

DOI : $10.4000 /$ ceb. 16002

ISSN : 2261-4184

Éditeur

INALCO

Édition imprimée

ISBN : 9782858313693

ISSN : 0290-7402

\section{Référence électronique}

Nicolas Pitsos, «L'Europe du Sud-Est et la presse allophone », Cahiers balkaniques [En ligne], 47 | 2020, mis en ligne le 21 août 2020, consulté le 06 juillet 2021. URL : http://journals.openedition.org/ceb/ 16002 ; DOI : https://doi.org/10.4000/ceb.16002

\section{(ब) $(1) \Theta$}

Cahiers balkaniques est mis à disposition selon les termes de la Licence Creative Commons Attribution - Pas d'Utilisation Commerciale 4.0 International. 


\title{
L'Europe du Sud-Est et la presse allophone
}

\author{
Nicolas Pitsos \\ CREE-Inalco
}

La péninsule des Balkans ou Europe du Sud-Est, aux frontières géopolitiques malléables, englobant dans la définition dominante de son extension maximale un espace inclus entre les Carpates et la Crète, la mer Adriatique et la mer Noire, réunissait au début du $\mathrm{XIX}^{\mathrm{e}}$ siècle des possessions ottomanes jouissant de divers degrés d'autonomie et des territoires administrés par les Habsbourg. Suite à une série de conflits intra et/ou interétatiques, connue dans le domaine des relations internationales sous le nom de «question d'Orient », plusieurs États ont été constitués tout au long du XIX ${ }^{\mathrm{e}}$ siècle et jusqu'à nos jours.

Tout au long de cette période, la presse connut aussi dans cette partie du continent européen un essor remarquable. Des éditions de journaux et de revues publiées en langues considérées comme officielles dans les différentes entités étatiques côtoyèrent des publications en langues « étrangères 》, telles que l'anglais, le français, l'italien ou d'autres langues pratiquées par des communautés linguistiques minoritaires et/ou d'immigrés s'installant dans les pays de cette région. En même temps, des individus originaires de l'Europe du Sud-Est, émigrant vers d'autres pays du continent, dont la France, étaient parfois à l'origine de la parution d'une presse publiée dans l'une des langues officielles des États balkaniques telles que l'albanais, le bulgare, le grec, le macédonien, le roumain, le serbo-croate-bosniaque, le slovène ou le turc. Élément constitutif de réseaux diasporiques ou vecteur de promotion d'intérêts politiques, économiques, culturels, la presse en langues étrangères, autres que celles établies comme officielles et/ou minoritaires, est susceptible de nous aider à mieux reconstituer la diversité sociale et culturelle des sociétés concernées. Au carrefour entre histoire de la presse, histoire de la circulation des savoirs, des discours et des pratiques, histoire de la mobilité socio-spatiale, ces supports sont très souvent les « oubliés » de la recherche historique en raison surtout de l'étrangeté de la langue dans laquelle ils 
CAHIERS BALKANIQUES

12

La presse allophone dans les Balkans

sont rédigés ou de leur place atypique dans l'écriture d'une histoire de la presse depuis la perspective de la langue officielle à l'échelle nationale.

Les textes publiés dans ce volume sont issus d'une journée d'étude organisée en juin 2017, par le Centre de recherche Europes-Eurasie (CREE) de l'Inalco et le Réseau pour l'étude de la presse en langues étrangères (Transfopress) rattaché au Centre d'histoire culturelle des sociétés contemporaines (CHCSC) de l'université de Versailles Saint-Quentin-en-Yvelines. Cette rencontre scientifique souhaitait pallier ces lacunes historiographiques et elle s'adressait à la fois à des spécialistes recouvrant l'espace de l'Europe du Sud-Est et à des chercheurs travaillant sur l'histoire de la presse en langues étrangères. À côté d'une réflexion sur l'emploi et la définition du terme de presse en «langues étrangères » dans le contexte d'entités politiques multilingues, tel l'Empire ottoman, l'Empire austro-hongrois ou les États qui en sont issus dans les Balkans, les contributions dans ce volume abordent plusieurs sujets : elles concernent la conception, l'organisation, la diffusion, la fonction et la réception de cette presse dans les deux sens, à savoir la presse publiée en « langues étrangères » dans les États balkaniques aux XIX ${ }^{\mathrm{e}}$ et $\mathrm{XX}^{\mathrm{e}}$ siècles, et la presse publiée dans l'une des langues officielles de ces États ailleurs dans le monde, notamment au sein de la société française. Parmi les aspects de ce phénomène traités par les auteurs, on peut citer : les types des publications, les personnes qui les ont initiées, les maisons d'édition ou de presse qui les ont lancées sur le marché, les langues dans lesquelles elles ont été rédigées, les réseaux qui les ont portées; on peut également observer leur longévité, leur chronologie, leur contenu, leurs lecteurs, le rôle de ces organes dans le mouvement général de circulation des hommes et de leurs idées, les transferts culturels auxquels ils ont donné lieu, les identités métissées générées, les stratégies de leurs acteurs dans la promotion des intérêts communautaires et/ou étatiques.

Une première série d'articles étudie la diffusion de la presse francophone en Europe du Sud-Est. Dans une telle perspective, Gérard Groc analyse les périodiques publiés en langue française au début de l'ère républicaine en Turquie. Despina Provata dresse une typologie de la presse éditée en français en Grèce, alors que Joëlle Dalègre l'illustre par l'un de ses représentants les plus emblématiques et diachroniques, le Messager d'Athènes. De son côté, Claudiu Topor inscrit dans la mécanique de propagande en temps d'occupation militaire la publication d'un journal en allemand en Roumanie pendant la Première Guerre mondiale. Nicolas Pitsos décline dans son article les utilisations de la presse publiée en langue française en Europe du Sud-Est au lendemain de la Grande Guerre en tant qu'outil de diplomatie culturelle. Oana Soare poursuit les trajectoires éditoriales de la presse en français en Roumanie de la seconde moitié du XIX ${ }^{\mathrm{e}}$ siècle, tandis qu'elle aborde également le destin des périodiques publiés en roumain à Paris par 
des révolutionnaires exilés à l'ère du « printemps des peuples ». Cette deuxième catégorie de textes, explorant la présence de journaux publiés à l'extérieur de la péninsule des Balkans dans une des langues officielles de cet espace, est enrichie par l'article de Dragan Bogojevic et d'Ivona Jovanovic consacré à la publication du journal officiel monténégrin à Paris entre 1917 et 1921. Aleksandra Kolakovic poursuit, quant à elle, les initiatives d'édition de périodiques en France par des émigrés serbes aussi bien dans le contexte yougoslave que celui succédant à l'éclatement de la fédération yougoslave. Svetla Moussakova se penche sur les trajectoires des revues publiées par des émigrés bulgares en Europe de l'Ouest et Zdravka Konstantinova introduit, avec son tableau de la presse publiée en langues étrangères en Bulgarie, le troisième volet du phénomène de la presse allophone en Europe du Sud-Est, à savoir les publications allophones dans un contexte linguistique inter-balkanique. Dans une telle optique, Évelyne Noygues se penche sur l'histoire de la revue Albanija à Belgrade, revue ayant servi d'instrument de construction d'une identité nationale albanaise. Enfin, Dragica Mugosa nous invite à redécouvrir les activités d'un réseau d'information alternatif qui, pendant les années 1990, a œuvré dans l'espace ex-yougoslave comme un moyen de communication internationale proposant des articles dans les langues officielles et non officielles des pays concernés. 